\title{
THE EFFECTS OF ACTIVATED CHARCOAL AND CALCIUM CARBONATE BASED TOOTHPASTES ON SURFACE PROPERTIES OF COMPOSITE RESIN RESTORATIVE MATERIALS
}

\author{
Nancy S. Farghal" and Hend E. Elkafrawy*
}

\begin{abstract}
Objectives: The aim of the study was to evaluate, in vitro, the surface roughness and microhardness of two different composite resin materials submitted to simulated tooth brushing with activated charcoal and calcium carbonate toothpastes.

Materials and Methods: Microfilled (Heliomolar) and nanohybrid (Tg-nanohybrid) composite resins were studied, 30 disc-shaped specimens were prepared from each composite, then divided to 3 groups ( $\mathrm{n}=10$ ); group A (control group): brushed with distilled water, group B: brushed with Perfect white (Black) ${ }^{\circledR}$ toothpaste group, and group C: brushed with Depurdent ${ }^{\circledR}$ toothpaste, with a powered toothbrush for 30 seconds daily for 7 days. Vickers Microhardness was measured at 10N load and the surface roughness was measured using a surface roughness tester, SEM examination of some selected samples after brushing was conducted. Two-way analysis of variance (ANOVA) and Kruskal-Wallis were used to analyze the data with 5\% level of significance between the means of tested groups.
\end{abstract}

Results: The two composites showed significant increase in surface roughness after brushing in all groups, the highest values occurred in nanohybrid/Depurdent group, while the lowest values were in microfilled/control group. Microhardness increased significantly in nanohybrid/Depurdent group and decreased in microfilled/Depurdent group, while no significant change in microhardness was noted after brushing with Perfect white (Black) in both composites compared to the control group.

Conclusion: The tested dentifrices significantly influenced the surface roughness and microhardness of microfilled and nanohybrid composite resins.

KEYWORDS: Activated charcoal, Calcium carbonate, Vickers microhardness, Surface roughness, Composite resin.

\footnotetext{
* Lecturer of Dental Biomaterials (PhD), Department of Dental Biomaterials, Faculty of Dentistry, Tanta University, Egypt.
} 


\section{INTRODUCTION}

The demand of the perfect aesthetic appearance is highly increasing. People are searching for the clean and beautiful teeth which will reflect their perfect smile. Today, many oral care products are introduced to the market and spread widely through the advertisement as being the solution to teeth stains and discolorations, which makes the choice more difficult for patients. Among these products are the dentifrices containing different abrasives, such as calcium carbonate and silica, and recently, activated charcoal ${ }^{1,2}$.

These dentifrices have an important role in cleaning teeth, removing bacteria and stains from the tooth surface. However, the dentifrice should promote optimal tooth surface cleaning with minimal abrasion ${ }^{3}$, since dentifrices with high amounts of abrasives can damage hard tissue, soft tissue and restorations, causing gingival recession, cervical abrasion, and dentin hypersensitivity ${ }^{4,5}$.

The newly introduced activated charcoal toothpastes have attracted interest. Activated charcoal has a high porosity, suitable for absorption in emergency medical situations regarding certain poisons. Its absorbing ability may produce ion exchange in the mouth via its nanosized pores that may bind and remove tooth-staining agents. Manufacturers claim that it has the capacity of adsorbing pigments, chromophores and stains responsible for the color change of teeth ${ }^{2}$.

Few studies have been conducted to evaluate the surface roughness of composite resins caused by some abrasive dentifrices. The dentifrices that used silica and carbonate were less abrasive compared to the ones containing bicarbonate ${ }^{6}$.

To our knowledge, few studies were performed to evaluate the abrasive effect of charcoal dentifrices on the integrity of composite resin restorations, this study aims to evaluate, in vitro, the surface roughness and hardness of two types of composite resin restorative materials submitted to simulated toothbrushing with a charcoal dentifrice compared to calcium carbonate containing dentifrice. The null hypothesis is that toothbrushing with dentifrices does not influence the surface roughness or microhardness of composite resins.

\section{MATERIALS AND METHODS}

Two commercial resin-based composites were analyzed; Heliomolar (Microfilled), and Tgnanohybrid (Nanohybrid). Two commercial abrasive toothpastes were used in this study; Activated charcoal toothpaste (Perfect white (Black) ${ }^{\circledR}$, and Cleaning and polishing toothpaste (Depurdent $\left.{ }^{\circledR}\right)$. The materials compositions are shown in Table 1.

\section{Specimens preparation}

Thirty disc-shaped specimens of each composite resin were made for each test. The specimens were prepared using split Teflon mold $(8 \mathrm{~mm}$ inner diameter and $2 \mathrm{~mm}$ thick) in two increments, each increment was light activated for 40 seconds (Spectrum 800, DENTSPLY). During the second incremental procedure, the composite resin surface was covered with a mylar strip. A glass slab was then placed on top of the mylar strip and pressed gently until it touched the top surface of the mold, after which the specimens were cured. The specimens were polished with silicon carbide papers;1200-4000 grit under water irrigation. Specimens were then removed from the molds and stored in distilled water at $37^{\circ} \mathrm{C}$ for 24 hours to ensure completed polymerization of the composites before brushing.

\section{Brushing of specimens}

Specimens were randomly divided into three groups $(n=10)$ (A: control group; where specimens were brushed with distilled water without adding any toothpaste, B: brushed with Perfect White (Black)® toothpaste, and $\mathrm{C}$ : brushed with Depurdent ${ }^{\circledR}$ 
TABLE (1) Materials used in this study.

\begin{tabular}{|c|c|c|c|c|}
\hline Material & Description & Composition & Manufacturer & Batch no. \\
\hline Heliomolar. & $\begin{array}{l}\text { Microfilled } \\
\text { composite resin. }\end{array}$ & $\begin{array}{l}\text { Bis-GMA, urethane dimethacrylate and } \\
\text { decandiol dimethacrylate }(22 \mathrm{wt} \%) \text {. Highly } \\
\text { dispersed silicon dioxide, ytterbium tri-fluoride } \\
\text { and copolymer }(0.02-0.04 \mu \mathrm{m}, 77.8 \mathrm{wt} \%) \text {. }\end{array}$ & $\begin{array}{l}\text { Ivoclar vivadent, } \\
\text { Schaan, Liechtenstein. }\end{array}$ & T34341. \\
\hline Tg-nanohybrid. & $\begin{array}{l}\text { Nano-hybrid } \\
\text { composite resin. }\end{array}$ & $\begin{array}{l}\text { Bis-GMA, Bis-EMA, TEGDMA. } \\
\text { TiO2, silica, Ba-B-F- Al-Si glass }(0.02-1 \mu \mathrm{m}, 75 \\
\text { wt } \%) \text {. }\end{array}$ & $\begin{array}{l}\text { Technical \& General, } \\
\text { London, UK. }\end{array}$ & 11-34B. \\
\hline $\begin{array}{l}\text { Perfect white } \\
\text { (Black)®. }\end{array}$ & $\begin{array}{l}\text { Activated } \\
\text { charcoal } \\
\text { toothpaste. }\end{array}$ & $\begin{array}{l}\text { Aqua, Sorbitol, Hydrated Silica, Glycerin, } \\
\text { Pentasodium Triphosphate, tetrasodium } \\
\text { Pyriphophate, Sodium Lauryl Sulphate, Aroma, } \\
\text { PEG-32, Cellulose Gum, Sodium Floride, } \\
\text { Cocomidopropyl Betaine, Sodium Saccharin, } \\
\text { Charcoal Powder, Limonene. }\end{array}$ & $\begin{array}{l}\text { Beverly Hills Formula, } \\
\text { Dublin 9, Ireland. }\end{array}$ & 764B. \\
\hline Depurdent ${ }^{\circledR}$. & $\begin{array}{l}\text { Cleaning and } \\
\text { polishing paste. }\end{array}$ & $\begin{array}{l}\text { Calcium carbonate, granules of pumice stone } \\
\text { (lapis pumicis), glycerin, silicon, titanium } \\
\text { dioxide, salt, limonene. }\end{array}$ & $\begin{array}{l}\text { Dr. Wild \& Co. AG, } \\
\text { Muttenz/Switzerland. }\end{array}$ & 02/0060. \\
\hline
\end{tabular}

toothpaste). Specimens were brushed using a powered toothbrush (Philips Sonicare - Diamond Clean Smart Toothbrush, Philips Oral Healthcare, LLC, Germany). Each time, the toothbrush head was loaded with the toothpaste of $0.25 \mathrm{mg}$ weight and placed against the specimen for 30 seconds daily for 7 days. While brushing, the specimens were placed in the mold, and the mold was fixed on the table so that the specimens were stable during the brushing cycle. After brushing, each specimen was rinsed under running water to remove toothpaste residues and stored in distilled water at $37^{\circ} \mathrm{C}$ until testing.

\section{Surface roughness testing}

A portable surface profile meter (PosiTector SPG, Deflesco, USA) with a contact stylus gauge, was used in this study to evaluate the surface roughness of the specimens. The device detects the surface roughness through measuring the depth of a single valley in relation to the height of the surrounding peaks using a pointed, cone-shaped probe. For each sample, the surface profile meter is calibrated to a zero point, then held vertically against the surface of the sample, when hearing a peep sound and a value appeared on the screen the device was moved to another point, the profile is being detected by recording the height difference between profile maximums and minimums (valleyto-peak) at each point, three different points were recorded for each sample, the device also stores the data and calculates the average surface roughness $(\mathrm{Ra}-\mu \mathrm{m})$ for each specimen.

\section{Microhardness testing}

Vickers Microhardness tester (Zwick Roell, INDENTEC, West Midlands, UK) was used to test the microhardness of the specimens in this study. A $136^{\circ}$ pyramidal diamond indenter was used on each specimen to form a square indent, using a 10-N load at room temperature. The indenter was pressed into the sample with an accurately controlled test force, that was maintained for a specific dwell time of 
15 seconds. The size of the indent was determined optically by measuring the two diagonals of the square indent. The Vickers hardness number is a function of the test force divided by the surface area of the indent. The average of the two diagonals were used to calculate the Vickers microhardness values using the following formula: $\mathrm{VHN}=1.854 \mathrm{~F} /$ $\mathrm{d} 2$ (where $\mathrm{F}$ is the load applied in Newtons and $\mathrm{d}$ is the mean length of the two diagonals of each indentation).

\section{Scanning Electron Microscopy}

One sample from each group was randomly selected for SEM examination (JSM 6510LA, JEOL, Japan), to observe the surface morphology of the samples after brushing. Specimens were gold sputter-coated and photographs were taken of representative areas at 100-fold magnification $(25 \mathrm{KV})$.

\section{Statistical analysis}

Means and standard deviations were calculated. Data statistically analyzed by an IBM compatible personal computer with SPSS statistical package version 20 (Released 2011; SPSS Inc., IBM Corp., Armonk, New York, USA). The KolmogorovSmirnov test was used to verify the normality of distribution. For surface roughness test, Two-way analysis of variance (ANOVA) and Bonferroni multiple comparison tests were performed to analyze the normally distributed data. For microhardness test, Kruskal-Wallis and Dunn's multiple comparison test were used to analyze not normally distributed data, with $5 \%$ level of significance between the means of tested groups.

\section{RESULTS}

\section{Roughness test}

Mean values and standard deviations of the roughness results are shown in (Table 2). There is a statistically significant difference among all the tested groups. The highest surface roughness occurred in nanohybrid/Depurdent group, while the lowest recorded roughness was in microfilled/ control group. The roughness of both microfilled and nanohybrid composites was highest when brushed with Depurdent followed by Perfect white and the least affected was the distilled water brushed (control) group.

\section{Vickers microhardness test}

Microhardness mean values and standard deviations are shown in (Table 3), in microfilled composite, a significantly lower microhardness value was in Depurdent (C) group, while no significant difference was recorded between the control (A) and Perfect white (B) groups. In nanohybrid composites, no statistically significant difference was also recorded between control (A) and Perfect white (B) groups, However, they were both significantly lower than the Depurdent (C) group. The lowest microhardness values were in microfilled/Depurdent, nanohybrid /control and nanohybrid/ Perfect white groups.

TABLE (2) Surface roughness ( $\mathrm{Ra}, \mu \mathrm{m})$ mean values and standard deviation of the resin-based composites.

\begin{tabular}{|c|c|c|c|c|}
\hline Material & $\begin{array}{c}\text { Control group (A) } \\
\text { (Distilled water). }\end{array}$ & $\begin{array}{c}\text { Group (B)Perfect } \\
\text { white (Black)®. }\end{array}$ & $\begin{array}{c}\text { Group }(\mathbf{C}) \\
\text { Depurdent }{ }^{\circledR}\end{array}$ & P-Value \\
\hline Heliomolar (Micro-filled Composite). & $0.098^{\mathrm{a}} \pm 0.021$ & $0.199^{\mathrm{b}} \pm 0.019$ & $0.396^{c} \pm 0.021$ & \multirow[b]{2}{*}{$0.000^{*}$} \\
\hline Tg-nanohybrid(Nano-hybrid Composite). & $0.238^{\mathrm{e}} \pm 0.020$ & $0.297^{\mathrm{f}} \pm 0.018$ & $0.474^{\mathrm{g}} \pm 0.061$ & \\
\hline
\end{tabular}

${ }^{*} \mathrm{P}<0.05$ significant difference.

Values with different lowercase letters indicate significant difference $(\boldsymbol{P}<0.05)$. 
TABLE (3) Vickers microhardness (VHN) mean values and standard deviation of the resin-based composites.

\begin{tabular}{|c|c|c|c|c|}
\hline Martial & $\begin{array}{l}\text { Control group (A) } \\
\text { (Distilled water) }\end{array}$ & $\begin{array}{c}\text { Group (B)Perfect } \\
\text { white (Black)® }\end{array}$ & $\begin{array}{c}\text { Group }(\mathrm{C}) \\
\text { Depurdent }{ }^{\circledR}\end{array}$ & P-Value \\
\hline Heliomolar (Micro-filled Composite) & $62.8^{\mathrm{ab}} \pm 1.873$ & $75.6^{\mathrm{a}} \pm 2.796$ & $45.1^{\mathrm{cd}} \pm 1.911$ & \multirow{2}{*}{$0.000^{*}$} \\
\hline Tg-nanohybrid (Nano-hybrid Composite) & $40.3^{\mathrm{c}} \pm 3.40$ & $40.9^{c} \pm 3.034$ & $57.4^{\text {bd }} \pm 3.657$ & \\
\hline
\end{tabular}

${ }^{*} \boldsymbol{P}<0.05$ significant difference.

Values with different lowercase letters indicate significant difference $(P<0.05)$. Values with the same lowercase letters indicate non-significant difference $(P>0.05)$.
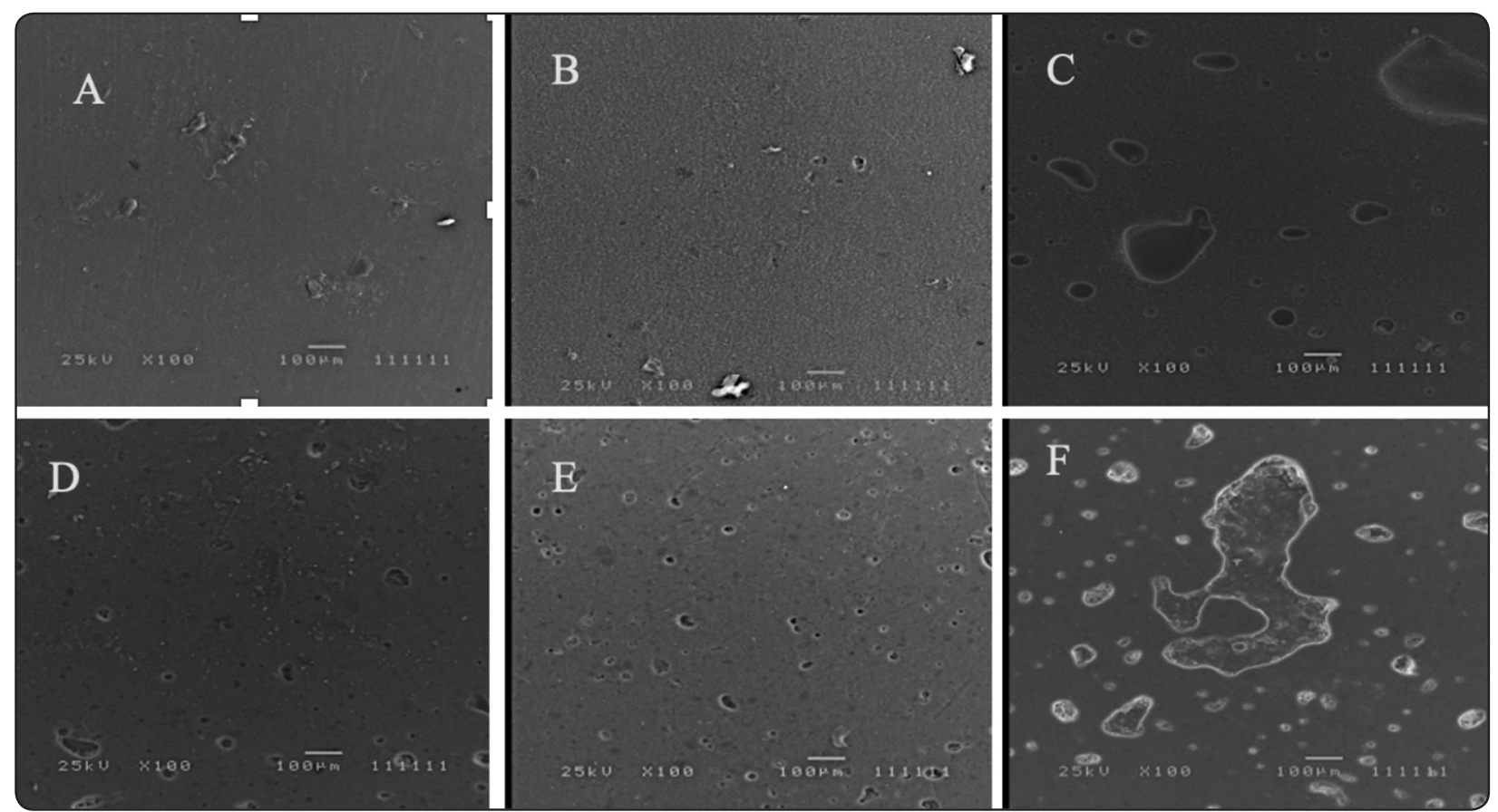

Fig. (1) Representative SEM (100x) micrographs of each composite resin. A, B and C represent Microfilled composite specimens after brushing with distilled water, Perfect white $(\text { Black })^{\circledR}$ and Depurdent ${ }^{\circledR}$ respectively. D, E and F represent Nanohybrid composite specimens after brushing with distilled water, Perfect white (Black) ${ }^{\circledR}$ and Depurdent ${ }^{\circledR}$ respectively.

\section{Scanning Electron Microscopy}

Representative SEM micrographs of the tested composite resins are shown in (Fig.1). The specimens showed surface changes ranging from filler protrusion (Fig. 1B), to combination of filler loss and wear of the resin matrix (Fig.1C, D, E and F). the surface changes are milder in (Fig.1D and E) and severe in (Fig.1C and F), while a smoother surface is noted on (Fig.1A).

\section{DISCUSSION}

The increased demand of the aesthetic appearance of teeth is becoming a priority in people's lives. Moreover, the emotional state is highly affected by the person's smile and the color of his teeth. Therefore, many people are using abrasive toothpastes at homes, to eliminate their teeth stains and get a brighter smile, however; the adverse effects of using these toothpastes on aesthetic restorations may outweigh the benefits it may produce as a whitening agent. 
The goal of this study was to observe changes in composite resin restorations roughness and microhardness, after brushing with a toothpaste containing activated charcoal, recently introduced to the market, compared to a calcium carbonate toothpaste. Few studies have been published studying the effects of charcoal activated tooth pastes on enamel ${ }^{6}$, however its effects on dental restorations is still unclear.

Microfilled and nanohybrid composites were selected in this study as they are among the most frequently used materials for building up anterior restorations, as they present low surface roughness after polishing ${ }^{7,89}$ and consequently better aesthetic appearance. The specimens were polished with 1200-4000 grit silicon carbide papers at the beginning of the experimental protocol, to minimize any initial surface roughness, so that the final results represent the actual material's behavior ${ }^{10}$.

In this study, an electric tooth brush was used, to simulate the clinical conditions, and give uniform brushing to all the specimens, a single operator performed the brushing procedures to minimize variations ${ }^{11}$. Specimens were stored in distilled water to avoid formation of any protective layer if stored in artificial saliva ${ }^{12}$.

The surface roughness of any dental restoration is clinically interpreted as the bacterial adhesion to its surface, and subsequently promotes the formation of oral biofilms which directly affects the periodontal health. A surface roughness above 0.2 $\mu \mathrm{m}$ has been reported to increase the colonization and adhesion of bacteria on composite surfaces ${ }^{13,14}$. It also changes the color and gloss of composite restorations and impair the esthetic appearance ${ }^{10,15,16}$.

In the current study, microfilled composite presented generally lower surface roughness than nanohybrid composite. SEM observation also showed that the microfilled material had less altered surface change after toothbrushing compared to the control group. This is probably related to the "organic filler" approach used in the microfilled composite manufacturing process, whereby filler and resin are mixed, cured, crushed and used for filling the final material ${ }^{17}$. Therefore, during abrasion, the microfilled composite probably did not undergo inorganic particle debonding and elution ${ }^{18}$, which could explain the slight alterations observed by SEM.

Although nanocomposites were introduced with the advantage of increased polish and gloss retention, as only small particles would be dislodged during wear, leaving the surfaces with defects smaller than the wavelength of light ${ }^{19}$, nanohybrids combine nanosized and conventional fillers. Thus, as evidenced by the present results, nanohybrid composite may still suffer from the loss of large filler particles ${ }^{18}$. This is probably the reason for the increased values of surface roughness and explains the SEM results. The loss of fillers during wear occurs due to a combination of normal loading and frictional shearing forces act on the wear surface. However, as fillers present higher elastic modulus than the resin matrix itself, they may bear the majority of these loads. Nonetheless, owing to the relatively weak bond between fillers and resin, most particles cannot withstand the combined action of normal and frictional forces. Thus, they are liable to be fragmented or dislodged. With an increasing dislodgement of fillers, fatigue cracks are more easily induced, and they develop between fillers and organic matrix. Therefore, the integrity of this matrix is gradually destroyed, causing the loss of material $^{20}$.

Both the charcoal activated and calcium carbonate toothpastes showed significant increase in surface roughness, compared to the control groups, however, the calcium carbonate had the greatest increase. Both the toothpastes had an abrasive effect on the resin matrix, leaving the filler exposed or dislodged. Pervious study also detected a significant increase in composite surface roughness after using calcium carbonate tooth paste ${ }^{21}$. Studies 
show that composite resin with a surface roughness value of more than $1 \mu \mathrm{m}$ can make patients feel uncomfortable, because the roughness is detectable by the tongue ${ }^{22}$, accordingly, the patient may not detect the roughness in the composite surface after using the tested toothpastes according the current study results.

The reason for choosing Vickers hardness over Knoop hardness in our study, is that, the Vickers hardness test is less sensitive to surface defects and conditions, and more sensitive to measurement errors when equal loads are applied due to its shorter diagonals ${ }^{23}$.

Microhardness values significantly decreased in microfilled composite after brushing with calcium carbonate toothpaste. however, a significant increase in microhardness was noted on nanohybrid group. This is possibly because the Depurdent toothpaste has more abrasive effect causing wear and loss of the resin matrix exposing the filler to the surface, so the Vickers indenter detected the hardness of the fillers of each composite. Previous studies showed no difference or improvement in microhardness ${ }^{24,25}$, others showed decrease in microhardness of composites after brushing with whitening toothpastes ${ }^{26}$. On the other hand, no significant change was noted between the charcoal activated and control groups in the two composites, indicating less destruction of the resin matrix by the charcoal activated toothpaste.

\section{CONCLUSION}

The null hypothesis of this study was rejected, toothbrushing with the tested dentifrices significantly influenced the surface roughness and microhardness of microfilled and nanohybrid composite resins, the patients should be informed to limit the use of these dentifrices or at least expect the damage that can affect the surface of their composite restorations. Further studies on other restorative materials with different brushing times and the possible color changes should be done.

\section{REFERENCES}

1. Cury JA, Rosing CK, Tenuta LM. Are dentifrices all the same? Int J Braz Dent 2010; 6:254-6.

2. Brooks JK, Bashirelahi N, Reynolds MA. Charcoal and charcoal-based dentifrices: A literature review. J Am Dent Assoc. 2017;148:661-70.

3. Wiegand A, Schlueter N. The role of oral hygiene: does toothbrushing harm? Monogr Oral Sci. 2014;25:215-9.

4. Kodaka T, Kuroiwa M, Kuroiwa M, Okumura J, Mori R, Hirasawa S, et al. Effects of brushing with a dentifrice for sensitive teeth on tubule occlusion and abrasion of dentin. J Electron Microsc. 2001;50:57-64.

5. De Menezes M, Turssi CP, Hara AT, Messias DC, Serra MC. Abrasion of eroded root dentine brushed with different toothpastes. Clin Oral Investig. 2004;8:151-5.

6. Pertiwi U I, Eriwati Y K and Irawan B. Surface changes of enamel after brushing with charcoal toothpaste. J. Phys.: Conf. Ser. 2017; 884

7. Jung M, Sehr K, \& Klimek J. Surface texture of four nanofilled and one hybrid composite after finishing. Operative Dentistry.2007;32(1) 45-52.

8. Senawongse P, \& Pongprueksa P. Surface roughness of nanofill and nanohybrid resin composites after polishing and brushing. J Esthe Rest Dent. 2007;19:265-73.

9. Janus J, Fauxpoint G, Arntz Y, Pelletier H, Etienne O. Surface roughness and morphology of three nanocomposites after two different polishing treatments by a multitechnique approach. Dent Mat. 2010;26:416-25.

10. Heintze SD, Forjanic M, Ohmiti K, Rousson V. Surface deterioration of dental materials after simulated toothbrushing in relation to brushing time and load. Dent Mater. 2010;26:306-19.

11. Nainan MT, Balan AK, Sharma R, Thomas SS, Deveerappa SB. The comparison of the effects of different whitening toothpastes on the micro hardness of a nano hybrid composite resin. J Conserv Dent. 2014;17:550-4.

12. Attin T, Hannig C, Wiegand A, Attin R. Effect of bleaching on restorative materials and restorations-A systemic review. Dent Mater. 2004;20:852-61.

13. Park J, Song C, Jung J, Ahn S, \& Ferracane J. The effects of surface roughness of composite resin on biofilm formation of streptococcus mutans in the presence of saliva. Oper Dent.2012;37:532-9. 
14. Bollen CM, Lambrechts P, Quirynen M. Comparison of surface roughness of oral hard materials to the threshold surface roughness for bacterial plaque retention: A review of the literature Dent Mater. 1997;13:258-69.

15. Cavalcante LM, Masouras K, Watts DC, Pimenta LA, \& Silikas N. Effect of nanofillers' size on surface properties after toothbrush abrasion. Am J Dent. 2009;22:60-4.

16. Lu H, Roeder LB, Lei L, \& Powers JM. Effect of surface roughness on stain resistance of dental resin composites. J Esthe and Rest Dent.2005; 17:102-8.

17. Nanocomposites. J Esthet Restor Dent. 2005;17:3-4

18. Moraes RR, Ribeiro Ddos S, Klumb MM, Brandt WC, Correr-Sobrinho L, Bueno M. In vitro toothbrushing abrasion of dental resin composites: packable, microhybrid, nanohybrid and microfilled materials. Braz Oral Res. 2008;22:112-8.

19. Mitra SB, Wu D, Holmes BN. An application of nanotechnology in advanced dental materials. J Am Dent Assoc. 2003;134:1382-90.

20. Hu X, Marquis PM, Shortall AC. Influence of filler loading on the two-body wear of a dental composite. J Oral Rehabil. 2003;30:729-37.
21. Ramadhani A M, Herda E, Triaminingsih S. The effect of brushing with toothpaste containing nano calcium carbonate upon nanofill composite resin surface roughness. J Physics: Conf. Series 1828344 (526071879) 012103

22. Anusavice K J, Shen C and Rawls H R. 2003 Phillips' Science of Dental Materials. 12th ed. St. (Louis: Elsevier) p 275-304.

23. Fuentes V, Tolledano M, Osorio R, Carvalho RM. Microhardness of superficial and deep sound human dentin. J Biomed Mater Res A. 2003;66:850-3.

24. Khamverdi Z, Kasraie Sh, Rezaei-Soufi L, Jebeli S. Comparison of the effects of two whitening toothpastes on micro hardness of the enamel and a microhybrid composite resin: An in vitro study. J Dent. 2010;7:139-45.

25. Nathoo SA, Chmielewski MB, Kirkup RE. Effects of Colgate platinum professional tooth whitening system on micro hardness of enamel, dentin and composite resins. Compend Suppl. 1994:S627-30.

26. Mohan Thomas Nainan, Ashok Kalappurakkal Balan, and Santhosh B Deveerappa. The comparison of the effects of different whitening toothpastes on the micro hardness of a nanohybrid composite resin J Conserv Dent. 2014; 17:550-554. 